\title{
Kırgızistan'ın Kuzey Bölgesinde Patates (Solanum tuberosum L.) Ekiliş Alanlarında Saptanan Bitki Paraziti Nematod (Nematoda: Tylenchida) Türleri
}

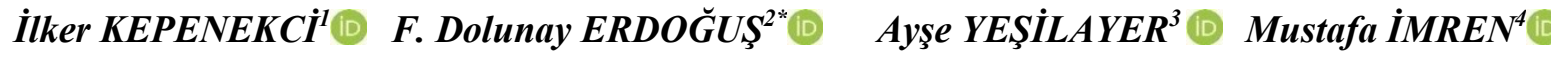 \\ ${ }^{1,3}$ Tokat Gaziosmanpaşa Üniversitesi, Ziraat Fakültesi, Entomoloji Bölümü, Tokat/TURKEY \\ ${ }^{2}$ Bitki Koruma Merkez Araştırma Enstitüsü, Ankara/TURKEY \\ ${ }^{4}$ Bolu Abant İzzet Baysal Üniversitesi, Ziraat ve Doğa Bilimleri Fakültesi, Bitki Koruma Bölümü, Bolu/TURKEY
}

\author{
${ }^{1}$ https://orcid.org/0000-0001-9847-6100 \\ ${ }^{2}$ https://orcid.org/0000-0002-8734-3422 \\ ${ }^{3}$ https://orcid.org/0000-0002-6654-5834 \\ ${ }^{4}$ https://orcid.org/0000-0002-7217-9092 \\ *Corresponding author (Sorumlu yazar): dolerkoll@gmail.com \\ Received (Geliş tarihi): 10.02.2021 Accepted (Kabul tarihi): 03.05.2021
}

\begin{abstract}
ÖZ: Bitki paraziti nematodlar kültür bitkilerinde ekonomik kayıplara neden olan zararlı organizmalardır. Bu çalışma Kırgızistan'in kuzeyinde yer alan Talas ve Tokmok Bölgeleri patates ekiliş alanlarında bulunan bitki paraziti nematod türlerini saptamak amacıyla yürütülmüş̧ür. Bu amaçla 2016 yıl yaz aylarında yapılan survey çalışmalarında patates ekiliş alanlarından 15 adet bitki ve toprak örneği alınmıştır. Örneklerden elde edilen bitki paraziti nematod türlerinin teşhisleri morfolojik ve morfometrik ölçümler yapılarak klasik yöntemlerle belirlenmiştir. Yürütülen teşhis çalışmaları sonucunda Tylenchida takımına ait 4 familya ve 6 cinse bağll 6 tür tespit edilmiştir. Bu türler Bitylenchus goffarti (Sturhan, 1966), Ditylenchus destructor (Thorne, 1945), Filenchus cylindricus (Thorne Malek, 1968), Helicotylenchus vulgaris (Yuen, 1964), Rotylenchus buxophilus ve Scutylenchus rugosus (Siddoqii, 1963)'dur. Çalışmada saptanan en yaygın türler ise F. cylindricus ve B. goffarti olarak kaydedilmiştir. Elde edilen tüm türler Kırgızistan için yeni kayıt niteliğinde olup D. destructor (patates çürüklük nematodu) patates bitkisinde önemli kayıplara yol açan bir zararlıdır.
\end{abstract}

Anahtar kelimeler: Patates, Kırgızistan, Tylenchida, bitki paraziti nematodlar.

\section{Plant Parasitic Nematode (Nematoda:Tylenchida) Species Determined in Potato (Solanum tuberosum L.) Cultivation Areas in the North Region of Kyrgyzstan}

\begin{abstract}
Plant parasitic nematodes are harmful organisms that cause economic losses in cultivated plants. This study was carried out to determine the plant parasitic nematode species found in potato cultivation areas of Talas and Tokmok Regions located in the North of Kyrgyzstan. For this purpose, 15 plant and soil samples were taken from potato cultivation areas during the survey studies conducted in the summer of 2016. The identification of the plant parasitic nematode species obtained from the samples was made by classical methods using morphological and morphometric measurements. As a result of the diagnostic studies carried out, 4 families belonging to the Tylenchida order and 6 species belonging to 6 genera were determined. These species are Bitylenchus goffarti (Sturhan, 1966), Ditylenchus destructor (Thorne, 1945), Filenchus cylindricus (Thorne Malek, 1968), Helicotylenchus vulgaris (Yuen, 1964), Rotylenchus buxophilus and Scutylenchus rugosus (Siddoqii, 1963). The most common species identified in the study were recorded as $\boldsymbol{F}$. cylindricus and B. goffarti. All the species obtained are new records for Kyrgyzstan and D. destructor (potato tuber nematode) is a pest causing significant losses in the potato plant.
\end{abstract}

Keywords: Potato, Kyrgyzstan, Tylenchida, plant parasitic nematodes. 


\section{GİRIŞ}

Nematodlar, hayvanlar âlemine bağl1, yaşama ortamı en geniş canlı gruplarından birisidir. Nematodların bitki ve hayvanlar üzerinde parazit olarak, toprakta ve mikroorganizmalar üzerinde ise serbest olarak yaşayan türleri vardır (Bernard, 1992; Boag ve Yeates, 1998). Nematodlar bitkilerin bulunduğu ve yaşayabildikleri bütün ortamlarda yaşama yeteneğine sahiptirler. Birçok nematod türü, bitkilerin çeşitli kısımlarında beslenir ve zarar oluştururlar. Bitki paraziti nematodlar (BPN) hemen hemen bütün kültür bitkilerine zarar verebilmektedirler. Tylenchida (Nematoda) takımı, bitkilerde ekonomik önemde zararlı türlerin büyük bir bölümünü içermesi nedeniyle bitki paraziti nematodlar içerisinde en önemli grubu oluşturmaktadırlar (Kepenekci, 2012).

Kırgızistan arazisinin \% 7'si tarım arazisidir. Çalışan nüfusun \% 33'ünü barındıran tarım sektörünün genel ekonomiye katkıs1 ise \% 40 civarındadır (Anonim, 2019b). Tarım faaliyetlerinin en yoğun olduğu yerler ülkenin güney batısındaki Oş ve Celalabad İlleri, Fergana Vadisi, kuzeyde Talas ve Çuy Vadileridir. Ayrıca Issık Göl çevresindeki tarım alanları da önemlidir. Tütün, pamuk, patates, üzüm, çilek, fasulye, sebzeler, meyveler ve şeker pancarı en çok yetiştirilen kültür bitkileri arasında yer almaktadır. Bunun yanı sıra buğday, arpa ve mısır gibi tahıl ürünleri de geniş ekim alanına sahiptir (Anonim, 2019a). Patates (Solanum tuberosum L.) önemli endüstri bitkilerinden birisi olup Solanaceae familyasına bağlı ve tek y1llık bir bitkidir. Toprak altında oluşturduğu yumrular hem depo, hem de vejetatif çoğalma organı olarak görev yapar. Patates çeşitli iklim bölgelerine kolaylıkla uyum sağlayabildiği için, dünyanın her yerinde başarıyla yetiştirilmektedir (Onaran, 2000). Kırgızistan'da 19. yüzyılda üretilmeye başlayan patates özellikle ülkenin kuzey bölgelerinde yetiştirilmektedir. Dünyanın 10. büyük patates üreticisi konumunda olan Kırgızistan'da 2018 y1lı patates üretimi 1.446.000 ton olarak bildirilmektedir (Anonim, 2019b). Kırgizistan patates tüketiminde Orta Asya'da birinci, dünya sıralamasında ise Beyaz Rusya'nın ardından ikinci sıradadır (Abdulhamidova ve ark., 2015). Patates, buğdayın ardından ülkedeki en önemli ikinci üründür. Ülkede patates üretimini sınırlayan faktörler arasında düşük toprak verimliliği ve tarlaların küçük oluşunun yanında en önemli problem hastalık ve zararlılardır (Abdulhamidova ve ark., 2015.) Patateste zarar yapan etmenler arasında nematodlar önemli bir yer tutmaktadır. Dünyada patates bitkisinde zarar oluşturan nematodlarla ilgili çalışmalar incelendiğinde başta patates çürüklük nematodu (Ditylenchus destructor Thorne, 1945) ve patates kist nematodlar1 (Globodera rostochiensis ve G. pallida) olmak üzere birçok nematod türünün, ürün kaybına yol açtığı bildirilmektedir (Winslow ve Willis, 1972; Evans ve Stone, 1977; Evans ve Trudgill, 1992). Yapılan literatür taramalarında bu güne kadar Kırgızistan'da patates ekiliş alanlarında bulunan bitki paraziti nematod türlerinin saptanması ile ilgili herhangi bir survey çalışmasına rastlanılmamıştır.

Bu araştırma kapsamında, Kırgızistan'ın kuzeyinde Talas ve Tokmok Bölgeleri, tarım alanlarında yetiştiriciliği yapılan patates (Solanum tuberosum L.) üretim alanları bitki paraziti nematodlar açısından incelenmiştir.

\section{MATERYAL ve METOT}

\section{Materyal}

Çalışmanın ana materyalini patates (Solanum tuberosum L.) ekim alanlarından alınan toprak ve bitki örnekleri ile bu örneklerde tespit edilen Tylenchida (Nematoda) takımına ait bitki paraziti nematod türleri oluşturmuştur.

\section{Yöntem}

\section{Arazi çalışmaları}

Toprak ve bitki örneklerinin alınması: Arazi çalışmaları 2016 yılı Haziran-Temmuz aylarında yürütülmüştür. Nematodların erginlerinin toprakta yoğun olarak bulunduğu bu dönemde Kırgızistan'ın patates üretimi yapılan alanlarına gidilerek toprak ve bitki kök örnekleri alınmıştır. Örnek alınan yerlerin seçiminde tüm yöreyi temsil edecek şekilde tesadüfi bir örnekleme yöntemi seçilmiştir. Her iki bölgede önemli patates ekiliş alanlarından 
İ. KEPENEKCI, F. D. ERDOĞUS, A. YESILILAYER, M. IMREN: KIRGIZISTAN'IN KUZEY BÖLGESINDE PATATES (Solanum tuberosum L.) EKILIŞ ALANLARINDA SAPTANAN BITKİ PARAZITI NEMATOD (NEMATODA: TYLENCHIDA) TÜRLERI

bölgeyi temsil edecek şekilde 3-4 ilçe ve her ilçede 3-4 köy belirlenmiştir. 0-10 dekara kadar olan alan bir birim kabul edilmiştir. $\mathrm{Bu}$ amaçla 15 adet patates ekiliş alanından örnekleme yapılmıştır (Çizelge 1). Örnekleme esnasında tarlanın içerisinde köşegenlerden girilerek zikzaklar çizilmiş ve 10-50 adımda bir bitki kök ve toprak sondası yardımı ile toprak örnekleri alınmıştır. Alınan örnekler homojen olacak şekilde karıştırılmış ve içerisinden ayrılan 1,5 kg'llk kısım polietilen torbalara konularak etiketlenmiştir. Örnekler araziden laboratuvara gelinceye kadar $4^{\circ} \mathrm{C}$ 'deki buz kutularında saklanmış ve laboratuvarda inceleme süresince yine aynı sıcaklıktaki buzdolabında bekletilmiştir.

Çizelge 1. Kırgızistan patates (Solanum tuberosum L.) alanlarından örnek alınan yerler ve alınan örnek sayıları.

Table 1. Sampling areas and number of samples taken from Kyrgyzstan potato (Solanum tuberosum L.) fields.

\begin{tabular}{lc}
\hline Bölge & Örnek sayisı \\
Area & Number of sample \\
\hline Talas & 8 \\
Tokmok & 7 \\
\hline
\end{tabular}

\section{Laboratuvar çalıșmaları}

Alınan örneklerden nematodlar ekstrakte edilmiş, fiksasyonları, preparatları yapılmış ve BPN'lerin morfolojik ve morfometrik karakterlere göre teşhisleri gerçekleştirilmiştir.

\section{Nematodlarm eldesi, fiksasyonu ve daimi preparatların yapımı}

Toprakta bulunan aktif nematodlarm eldesi: $\mathrm{Bu}$ amaçla modifiye edilmiş "Baermann funnel" metodu kullanılmıştır (Christie ve Perry, 1951). Bu metoda göre $200 \mathrm{~cm}^{3}$ toprak örneğinden elde edilen $10 \mathrm{ml} \mathrm{su}$ içerisindeki nematodlar toplanmıştır. Elde edilen nematodların cins düzeyinde teşhisleri yapıldıktan sonra BPN'leri içeren gruplar tür teşhisi amaciyla toplanarak fiksasyonu ve daimi preparasyonu yapılmıştır. Nematodların fiksasyonunda De Grisse (1969)'in geliştirmiş olduğu "Fiksasyon" yönteminden yararlanılmıştır. Daimi preparatların yapımında kullanılacak olan lamlar, "balmumu yüzük (Wax-ring)" yöntemi uygulanarak hazırlanmıştır (Hooper, 1986). Ayrıca türlerin örneklerdeki dağılımına göre bulunuş oranları ortaya koyulmuştur.
Kist nematodlarının topraktan eldesi: Toprakta bulunan kistlerin eldesinde Fenwick cihazı kullanılmıştır (Fenwick, 1940). Bunun için her örnekten $250 \mathrm{~g}$ toprak örneği alınmış kurutulduktan sonra cihazın üzerine yerleştirilmiş kaba elek içerisine dökülmüş ve üstten hortum yardımıyla orta basınçta yıkanarak taş vb. maddelerden temizlenmiştir. $\mathrm{Bu}$ işlem sırasında cihazın oluğundan taşırılan sular, kistlerin elde edilmesi amaciyla $850 \mu \mathrm{m}$ ve $250 \mu \mathrm{m}$ 'lik elekler üzerine akıtılmış, berrak su akmaya başladıktan sonra yıkama işlemi durdurulmuştur. $250 \mu \mathrm{m}$ 'lik elek üzerinde kalan kısım 100 ml'lik behere alınmış ve elde edilen solüsyon mikroskop altında incelenerek kistler aranmıştır.

\section{Teşhis çalışmaları}

Nematodların teşhisinde büyük ölçüde önemli olan ölçümler, Siddiqi (2000)'den alınan standart formüllere göre hesaplanmıştır. Buna ilaveten ölçüm değerlerinin Fortuner (1984)'e göre \%95 olasılıkla standart hatas1 istatistiki olarak hesaplanmıştır. Çalışma sonucu saptanan türlerin sistematikteki yerleri Siddiqi (2000)'ye göre verilmiştir.

Türlerin örneklerdeki dağılımına göre bulunuş oranları (Nematod saptanan örnek sayısı X 100/ Toplam örnek sayısı) \% olarak ortaya koyulmuştur.

\section{BULGULAR ve TARTIȘMA}

Araştırmada saptanan bitki paraziti nematodlar faunistik ve taksonomik olarak iki aşamada incelenmiştir. Çalışma sonucunda Tylenchida (Nematoda) takımından 6 cinse bağlı 6 tür saptanmıştır (Çizelge 2). Bu türler Bitylenchus goffarti, Ditylenchus destructor, Filenchus cylindricus, Helicotylenchus vulgaris, Rotylenchus buxophilus, Scutylenchus rugosus'tur. Çalışmada saptanan en yaygın türler ise $F$. cylindricus ve $B$. goffarti olarak belirlenmiştir. Elde edilen tüm türler Kırgızistan tarım alanlarında ilk defa bu çalışma ile ortaya koyulmuştur. 
Çizelge 2. Kırgızistan patates (Solanum tuberosum L.) üretim alanlarından elde edilen Tylenchida (Nematoda) takımına ait BPN türleri, bulunduğu örnek sayısı ve bulunma oranları.

Table 2. Plant parasitic nematode species belonging to Tylenchida (Nematoda) order obtained from potato (Solanum tuberosum L.) production areas in Kyrgyzstan.

\begin{tabular}{lcc}
\hline Nematod türleri & Bulunduğu örnek sayıs & Oranı (\%) \\
Nematode species & Number of samples found & Rate $(\%)$ \\
\hline Filenchus cylindricus $(\mathrm{Wu})$ Siddiqi & 12 & 80,0 \\
Bitylenchus goffarti (Sturhan) Siddiqi & 10 & 66,6 \\
Ditylenchus destructor Thorne & 4 & 26,6 \\
Helicotylenchus vulgaris Yuen & 2 & 13,3 \\
Scutylenchus rugosus Siddiqi & 2 & 13,3 \\
Rotylenchus buxophilus Golden & 1 & 6,6 \\
\hline
\end{tabular}

Çalışma sonucunda $F$. cylindricus $\% 80$ ile diğer türlere oranla en yoğun tespit edilen tür olurken bunu \%66,6 ile B. goffarti takip etmiştir (Çizelge 2). Çalışmada tespit edilen türlerden $D$. destructor (Patates çürüklük nematodu) patates için önemli bir zararlıdır.

Ayrıca alınan örneklerden kist nematodları (Globodera rostochiensis ve G. pallida)'na ait kistler elde edilmiştir. Ancak yapılan inceleme sonucunda kistlerin boş olduğu görülmüş bu nedenle hangi tür oldukları ile ilgili olarak kesin kanıya gidilememiştir. Patatesin en önemli zararlılarından olan bu grubun Kirgizistan'da tespitine yönelik çalışmaların ivedilikle yapılması karantina önlemleri açısından oldukça önemlidir.

Bugüne kadar Kırgizistan'da yapılan nematolojik çalışmalar ve tespit edilen nematod türleri (Bitki paraziti, virüs vektörü ve entomopatojen nematodlar) incelendiğinde; Kepenekci ve İmren tarafindan yürütülen çalışmada Talas ve Tokmok'dan alınan toplam 59 adet toprak ve bitki örneği incelenmiş ve Longidoridae ve Trichodoridae familyalarına ait 4 önemli virüs vektörü nematod türü saptandığı bildirilmiştir. Çalışmada saptanan türler şeker pancarında Longidorus elongatus (de Man) Micoletzky, kayısıda L. macrosoma Hooper, çilekte Xiphinema diversicaudatum (Micoletzky) Thorne ve patateste Trichodorus similis Seinhorst olarak bildirilmiştir (Kepenekci ve İmren, 2017).

Talas Bölgesi Akkorgon ve Kenesh köyleri fasulye ekiliş alanlarında 2016 yılında yürütülen başka bir çalışmada Thylenchida takımdan 12 cinse bağlı 16 tür saptanmıştır. Saptanan türler Bitylenchus duplexa; Boleodorus (B.) thylactus; Ditylenchus dipsaci; D. myceliophagus; Filenchus filiformis; $F$. thornei; Helicotylenchus dihystera; Hoplolaimus galeatus; Irantylenchus clavidorus; Merlinius brevidens; Paratrophurus loofi; Pratylenchus neglectus; $P$. pratensis; $P$. thornei; Psilenchus hilarulus ve Quinisilcius capitatus olarak bildirilmiştir (Kepenekci ve Erdoğuş, 2017).

Yapılan başka bir çalıșmada Talas ve Tokmok’ta bulunan meyve ve sebze ekiliş alanları Meloidogyne spp. (Kök ur nematodları) yönünden incelenmiştir. Çalışma sonucunda çilek, kayısı ve fasulyelerde Meloidogyne incognita ve M. javanica tespit edilmiştir (Kepenekci ve Döölötkeldiyeva, 2017).

Talas ve Tokmok bölgeleri şeker pancarı ve buğday ekim alanlarının Heterodera spp. (Kist nematodları) yönü ile incelendiği başka bir çalışmada ise şekerpancarı ekim alanlarında Heterodera schachtii Schmidt, 1871 buğday ekim alanlarında ise Heterodera avenae (Wollenveber, 1924) saptanmıştır (Kepenekci ve ark., 2017a).

Entomopatojen nematodların belirlenmesi amaciyla Kuzey Kirgizistan'da yürütülen çalışmada alınan 41 adet toprak örneği incelenmiş ve örneklerin \%7'sinde entomopatojen nematodlara rastlanmıştır. Yapılan teşhis çalışmaları sonucunda türlerin Heterorhabditis bacteriophora (KG81) ve Steinernema feltiae (KG3) olduğu belirtilmiştir (Kepenekci ve ark., 2017b)

Yapılan taramalarda 2017 yılından önce ülkede yapılan nematolojik bir çalışmaya rastlanmamıştır. Bunun sebebi nematoloji konusunda çalıșan uzman araştırmacıların bulunmamasıdır. Bu nedenle gerek bu çalışmada gerekse yukarıda belirtilen çalışmalarda elde edilen tüm türler Kırgızistan için yeni kayıt niteliği taşımaktadır. 
İ. KEPENEKCİ, F. D. ERDOĞUS, A. YESSILAYER, M. IMREN: KIRGIZISTAN'IN KUZEY BÖLGESINDE PATATES (Solanum tuberosum L.) EKILIŞ ALANLARINDA SAPTANAN BITKİ PARAZITI NEMATOD (NEMATODA: TYLENCHIDA) TÜRLERI

Patates ekim alanlarında yapılan bu çalışma ülkede nematolojik olarak patates ekim alanlarında yürütülen ilk çalışma olması nedeniyle elde edilen sonuçların Kırgızistan'da patates yetiştiriciliği yapan üreticilere son derece yararlı olacağ düşünülmektedir. Ayrıca elde edilen çıktıların

\section{LITERATÜR LISTESI}

Anonim. 2019a. Kırgızistan pazar bilgileri. T.C. Ticaret Bakanlığı Dış Temsilcilikler ve Uluslararası Etkinlikler Genel Müdürlüğü, Ankara.

Anonim. 2019b. https://kgturizm.tr.gg/Tar\%26\%23305\%3Bmve-Hayvanc $\% 26 \% 23305 \% 3 \mathrm{Bl} \% 26 \% 23305 \% 3 \mathrm{Bk}$.htm.

Abdulhamidova, D., T. Abdurakhmanova and P. Monneveuxc. 2015. Potato in Kyrgyzstan: The second bread Manas. Journal of Agriculture and Life Sci. 5(1): 5463.

Bernard, E. C. 1992. Soil nematode. Biodiversity Biology and Fertility of Soils. 14: 99-103.

Boag, B., and G. W. Yeates. 1998. Soil nematode biodiversity in terrestrial ecosystems. Biodiversity and Conservation. 7(5): 617-630.

Christie, J.E. and V.G. Perry. 1951. Removing nematodes from soil. Proc. Helminthol. Soc. Wash. 18, 106-108.

De Grisse, A. 1969. Redescription on modifications de quelque tecniques utilisees dans l'etude des neematodes phytoparasitaires. Meded. Ritksfac. Landwet. Gent, 34(2): 351-359.

Evans, K., and A.R. Stone. 1977. A review of the distribution and biology of the potato cyst nematodes Globodera rostochiensis and G. pallida. International Journal of Pest Management. 23:178-189.

Evans, K. and D L. Trudgill. 1992. Pest aspects of potato production Part 1. pp.438-475. In: P.Harris (Ed.) The Nematode Pests of Potatoes. Hill London.

Fenwick, D.W. 1940. Methods for the recovery and counting of cysts Heterodera schachtii from soil. Journal of Helminthology.18, 155-172.

Fortuner, R. 1984. Statistics in taxonomic descriptions. Nematologica. 30; 187-192.

Hooper, D.J. 1986. Handling fixing, staining and mounting nematodes. pp. 59-80. In: J.F. Southey (Ed.). Laboratory Methods Work With Plant and Soil Nematodes. Her Majesty's Stationery Office, London. birçok bakımdan yalnızca Kırgızistan için değil aynı zamanda başta komşu ülkeler olmak üzere diğer ülkeler açısından da önemli olduğu ve elde edilen çıktılar doğrultusunda yeni araştırmaların yapılmasının gündeme geleceği düşünülmektedir.

Kepenekci, İ. 2012. Nematoloji (Bitki Paraziti ve Entomopatojen Nematodlar) Eğitim, Yayım ve Yayımlar Dairesi Başkanlığı. Tar. Bil. Serisi Yayın No:3. Yenimahalle, Ankara.

Kepenekci, İ. and T. Döölötkeldiyeva. 2017. Determination of root-knot nematodes (Meloidogyne spp.) in vegetable and fruit cultivation areas in Talas and Çuy valleys north of Kyrgyzstan. 2nd International Balkan Agriculture Congress. 16-18 Mayıs 2017. Tekirdağ. p.129.

Kepenekci, İ. ve D. Erdoğuş. 2017. Plant parasitic nematodes of Tylenchida (Nematoda) associated with beans (Phaseolus vulgaris) growing areas in the North of Kyrgyzstan. Ecology Congress. 11-13 May1s 2017. Kayseri. p. 263.

Kepenekci, İ. ve M. İmren. 2017. Virüs vektör nematod (Dorylaimida: Nematoda) türlerine ait ilk rapor, Kuzey Kirgızistan. Ecology Congress. 11-13 May1s 2017.Kayseri. s.579.

Kepenekci, İ., H.D. Sağlam, M. İmren, and T. Döölötkeldi 2017a. Determination of cyst nematodes (Heterodera spp.) in sugar beet and wheat cultivation areas in the north of Kyrgyzstan. International Advanced Researches Engineering Congress. 16-18 Kasım Osmaniye. p. 2420.

Kepenekci, İ., H. Çimen, A. Akın, and S. Hazır. 2017b. First report of entomopathogenic nematodes (Nematoda) in Kyrgyzstan. $6^{\text {th }}$ Entomopathogens and Microbial Control Congress. 16-18 Eylül 2017. Tokat. p.85.

Onaran, H. 2000. Patates Tarımı, Sorunları ve Çözüm Yolları Niğde.

Siddiqi, M.R. 2000. Tylenchida Parasites of Plants and Insects. Cabi Publishing. UK.

Winslow, R.D. and R.J. Willis. 1972. Nematode diseases of potatoes. pp. 17-49. In: J. J. Webster, (ED.). Economic Nematology. Academic Press London, New York. 